Sólo cuento. Año VI, Tomo VI. México: Universidad Nacional Autónoma de México, 2014, 354 pp. ISBN 9786070252914

\title{
Pablo Brescia
}

University of South Florida. Florida, Estados Unidos pbrescia@usf.edu

\section{$\mathrm{E}$} N ESTE VOLUMEN encontramos una meritoria solución de continuidad: desde el año 2009, la Dirección de Literatura de la Universidad Nacional Autónoma de México se ha propuesto y ha conseguido relevar el campo de la cuentística hispánica reuniendo, como dice Rosa Beltrán en su presentación, "los mejores relatos de escritores vivos y en plena producción" (ix). Estos 27 relatos se ofrecen como una muestra del momento actual del cuento hispánico. Este hecho sitúa al libro en cierto tipo de circulación cultural contemporánea, o sea: se resiste a la unidad autorial, generacional, estilística o temática y propone en cambio una unidad múltiple a partir de los cuentos que la integran. Aquí conviven autores y autoras de reconocida trayectoria (Diamela Eltit, Carmen Boullosa, Luisa Valenzuela) con otros más jóvenes que han sabido recibir la aprobación de críticos y lectores (Pedro Mairal, Andrea Jeftanovic, Alejandro Zambra).

Se advierte además una tendencia a reforzar la presencia del Caribe y de Centroamérica en el libro (siete de los 27 autores son de esa procedencia). Hay, también, sorpresas agradables, que apuntan a la inclusión y al intercambio: tres autores españoles, una autora brasileña-ecuatoriana y un autor de Guinea Ecuatorial. Así, la antología intenta evadir tanto las líneas hegemónicas del mercado como las aspiraciones académicas rígidas y el resultado es bastante refrescante: el libro es ecléctico y misceláneo, un regalo para aquel lector o lectora de cuentos que sólo desea sumergirse en el mundo de la historia bien contada que nos aleja de las limitaciones de tiempo y espacio.

Los pre-textos del volumen tienen su propio peso. Mayra Santos, a 
quien debemos la compilación, transita por la palabra "agradecimiento": a los participantes de la antología y muy especialmente a la estudiante que la ayudó a confeccionarla. En su estudiante dice ver "el futuro de mi especie” y cierra su intervención esperanzada. Rosa Beltrán apunta a la calidad del material reunido, a la amplitud geográfica y a la repetición de algunos temas: identidad, afectos, problemas sociales e históricos. Cierra comentando: "los lectores encontrarán vía libre a las distintas formas de reflexión y asombro" (x). El prólogo es de José Edmundo Paz Soldán, quien habla de "momento notable" del cuento hispano y condensa la propuesta del libro: un "catálogo de formas narrativas de encarar el género" (xi, xiii). En la esperanza de Santos, en la libertad de la lectura de Beltrán y en la diversidad de la forma del cuento de Paz Soldán se encuentran algunas de las claves para entrar a Sólo cuento 6.

La antología traza un mapa e invita a los lectores y lectoras a ocupar y definir los territorios. Por razones de espacio, comentaremos dos cuentos representativos de cada sección. La primera región se titula "Muertos de verdad" y ¿quién puede culpar a los cuentistas de gravitar irremediablemente hacia la muerte como tema y problema? Allí aparecen seis cuentos. En "A la sombra de dos gatos por uno", la mexicana Carmen Boullosa propone un recuerdo infantil que se remonta a una pesadillesca cena navideña de 1970. Los hijos son seis, la madre ha muerto pero transita la casa como fantasma, y hay un padre que ha perdido el rumbo y una madrastra joven y malvada. Y también hay un gato llamado Vaca porque es blanco y negro y dos empleadas domésticas y una escena sórdida que involucra un cordón umbilical. La dicción de Boullosa es certera en la recuperación de la naturalidad con la que los niños cuentan el asombro y la crueldad. Por otra parte, en "Los conquistadores" José Ovejero intenta parodiar los lugares comunes del turista europeo de visión colonizadora y para muestras basta esta frase: "No sólo vivimos a costa de los países pobres, sino que además nos follamos a sus mujeres a cambio de calderilla" (78). El narrador es español y escritor; el espacio es el interior de la isla de Cuba; la trama tiene que ver con una búsqueda de datos sobre los revolucionarios (nos preguntamos si ellos son los muertos que justificarían la inclusión de este cuento en esta sección) y también con atisbos de relaciones sexuales; el relato pierde en algún momento su tensión y ya no la recupera, aunque el final sea digno de la escuela escatológica de cierta tradición literaria española. 
En la sección "Autores como sombras" aparecen siete cuentos donde los personajes escriben o intentan escribir. En el caso de "El hipnotizador personal" del argentino Pedro Mairal, bajo una historia de amor juvenil no correspondido -Pedro y Verónica se conocen en un taller literario- se deja caer como al pasar una reflexión sobre el tiempo, como si Mairal siguiera las huellas de un filósofo posmoderno entrenado por Bergson: la chica buscaba alguien que le anulara "el tiempo muerto" (123); vivía "desfasada del presente, un poco corrida hacia el futuro" (124). Como era de esperarse, el cuento contiene un cuento sobre un hipnotizador personal. El segundo cuento de esta sección, "La llamada telefónica”, del oriundo de Guinea Ecuatorial César Augusto Mba Abogo, es en muchos sentidos ejemplar: está lleno de referencias literarias -el personaje es escritor y lector, menciona a Hemingway, a Faulkner, a Vallejo, a Mistral, a Kafka, a D.F. Wallace, a Bolaño-, y culturales -los hermanos Cohen, Sade-, pero trata con delicadez y verosimilitud dos temas de nuestros tiempos y de todos los tiempos: la discriminación e intolerancia y el problema del trabajo, en este caso desde la óptica de un licenciado en Derecho que tiene la desgracia de ser un africano negro residente en Barcelona. La manera en que el narrador nos alarga la identidad y el contenido de esa llamada de "número fijo desconocido" (141) es digna de aquella definición borgeana del hecho estético como la inminencia de una revelación que no se produce.

En la sección "El mundo de afuera", son siete los cuentos. Dos son buenos ejemplos de maneras distintas de encarar el género. El del dominicano Pedro Antonio Valdez, "Carretera en el polvo", propone un escenario rural para una estructura clásica, de revelación final, anticipada desde el epígrafe del Génesis. En la historia polifónica del narrador, Bertoldo y su esposa, nos encontramos con un secreto que una voz se niega a divulgar y que cae como guillotina cruel e inevitable a la vez. Pero si el desplazamiento de voces es aquí el punto fuerte, en "Tesis sobre el equilibrio del mundo", de la argentina Betina González, domina una sola voz, la de la "joven sin atributos" que quería ser como Leila Ott, su vecina de la planta baja. Pleno de marcas culturales e intertextualidades -entre ellas What ever happened to Baby Jane película protagonizada por Bette Davis y Joan Crawford-, en este relato el suspenso pende del hilo de la identidad del personaje, acechado mediante un motivo literario reconocible - la espía que abre cartas e intenta descifrar la vida contenida en ellas. Los mundos externos pueden ser aquí los otros. 
La sección final del libro tiene como título "Zozobras" y contiene siete cuentos. En "El 34", del chileno Alejandro Zambra, vemos una muestra más de su estilo: la naturalidad melancólica con la que nos acerca a lo narrado. Aquí nos lleva a los tiempos de la escuela primaria y a un misterioso alumno (el 34 del título) que se la pasa repitiendo de grado y que, sin embargo, ejerce un extraño y hasta cómico influjo sobre sus compañeros: "en sus palabras latía un tiempo lento y maduro", dice el narrador (280). No hay revelación ni sorpresa en Zambra; hay, en cambio, una lenta resignación que nos lleva a la inevitabilidad del final. $Y$, en un viraje de tono que hace zozobrar al lector, leemos de la dominicana Rita Indiana Hernández "El ruido y la compasión en el Three Lakes Soccer Park". Escritora y música, Hernández ha vuelto a la ficción y en este cuento que ocurre en Miami hay una mezcla de nacionalidades (uruguayos, dominicanos, argentinos, venezolanos, brasileños, peruanos, puertorriqueños, mexicanos), de lenguas (el inglés, las variantes del español americano) y de marcas culturales (Angry Birds, Whole Foods, etc.) que, aunque por momentos entorpece la sintaxis, es realmente explosiva. Es una historia de relaciones, más que amorosas, sexuales, y, aunque a veces nos preguntamos cómo hacen estos personajes para fornicar casi todo el tiempo, esas relaciones están descritas sin eufemismos y con humor, y esto las hace irresistibles. Vaya una muestra de la dicción de Hernández: "A los veinte minutos de hablarme sucio en el oído, con la elocuencia de todos los cueros que en Amsterdam hacen ondear nuestra bandera, la ñema me dolía en el pantalón" (294).

A juzgar por Sólo cuento 6, el cuento, género proteico por excelencia, sigue desafiando cánones, diversificando geografías y estableciendo una continuidad en la creación literaria que es uno de los puntos más altos de la literatura hispanoamericana actual. Más allá de la libertad de la forma, el delicado balance entre lo centrípeto y lo centrífugo parece desvelar a los practicantes del cuento y tal vez residan allí las posibles re-significaciones del "efecto único" que planteara Edgar Allan Poe hace más de 170 años. Por eso surge la pregunta: ¿̇uede la forma del cuento apostar por la experimentación siendo cultora de una férrea urdimbre estructural? Los relatos de esta antología son diversos y no se atan a ninguna receta, pero siguen, tal vez sin saberlo, las ideas de Julio Cortázar, quien hablaba de la prodigiosidad del buen cuento que lograba una "apertura significativa" iluminando espacios que el lector debería rellenar, posibilitándonos la salida de la vida 
y luego la entrada, porque, como él mismo decía, la experiencia del cuento es como un acto de amor del cual se sale agotado "fuera del mundo circundante, al que vuelve poco a poco con una mirada de sorpresa, de lento reconocimiento". En una actualidad donde cabe preguntarse si la lectura quedará reducida a los "me gusta" de Facebook o directamente a las imágenes de Instagram, cabe apostar por estos relatos que nos piden que, como los seres de antaño, nos reunamos alrededor del fuego, y escuchemos. 